\title{
Development of a Real-Time Surface Solar Radiation Measurement System Based on the Internet of Things (IoT)
}

\author{
Álvaro B. da Rocha ${ }^{1}$, Eisenhawer de M. Fernandes ${ }^{1}$, Carlos A. C. dos Santos ${ }^{2, * \mathbb{C}}$, Júlio M. T. Diniz ${ }^{3}$ \\ and Wanderley F. A. Junior ${ }^{1}$ \\ 1 Academic Unit of Mechanical Engineering, Federal University of Campina Grande, Campina Grande, \\ Paraíba 58429-900, Brazil; alvarobarbosa2@hotmail.com (Á.B.d.R.); eisenhawer@ee.ufcg.edu.br (E.d.M.F.); \\ wanderley.ferreira@ufcg.edu.br (W.F.A.J.) \\ 2 Academic Unit of Atmospheric Sciences, Federal University of Campina Grande, Campina Grande, \\ Paraiba 58429-900, Brazil \\ 3 School of Apprentices-Sailors of Pernambuco, Navy of Brazil, Olinda, Pernambuco 53110-901, Brazil; \\ julio.tavares@marinha.mil.br \\ * Correspondence: carlos.santos@ufcg.edu.br
}

Citation: Rocha, Á.B.d.; Fernandes, E.d.M.; Santos, C.A.C.d.; Diniz, J.M.T.; Junior, W.F.A. Development of a Real-Time Surface Solar Radiation Measurement System Based on the Internet of Things (IoT). Sensors 2021, 21, 3836. https://doi.org/10.3390/ s21113836

Academic Editor: Xiangao Xia

Received: 27 April 2021

Accepted: 29 May 2021

Published: 1 June 2021

Publisher's Note: MDPI stays neutral with regard to jurisdictional claims in published maps and institutional affiliations.

Copyright: (c) 2021 by the authors. Licensee MDPI, Basel, Switzerland. This article is an open access article distributed under the terms and conditions of the Creative Commons Attribution (CC BY) license (https:/ / creativecommons.org/licenses/by/ $4.0 /)$.

\begin{abstract}
The determination of the levels of solar radiation incident on the terrestrial surface $\left(\mathrm{W} \cdot \mathrm{m}^{-2}\right)$ is essential for several areas such as architecture, agriculture, health, power generation, telecommunications, and climate forecasting models. The high cost of acquiring and maintaining radiometric equipment makes it difficult to create and expand monitoring networks. It contributes to the limited Brazilian radiometric network and affects the understanding and availability of this variable. This paper presents the development of a new surface solar radiation measurement system based on silicon photodiodes (Si) with a spectral range between $300 \mathrm{~nm}$ and $1400 \mathrm{~nm}$ incorporating Internet of Things (IoT) technology with an estimated cost of USD 200. The proposed system can provide instantaneous surface solar radiation levels, connectivity to wireless networks and an exclusive web system for monitoring data. For the sake of comparison, the results were compared with those provided by a government meteorology station (INMet). The prototype validation resulted in determination coefficients $\left(\mathrm{R}^{2}\right)$ greater than 0.95 while the statistical analysis referred to the results and uncertainties for the range of $\pm 500 \mathrm{~kJ} \cdot \mathrm{m}^{-2}$, less than $4.0 \%$ for the developed prototypes. The proposed system operates similarly to pyranometers based on thermopiles providing reliable readings, a low acquisition and maintenance cost, autonomous operation, and applicability in the most varied climatological and energy research types. The developed system is pending a patent at the National Institute of Industrial Property under registration BR1020200199846.
\end{abstract}

Keywords: surface solar radiation; low-cost sensor; real-time; pyranometer; Internet of Things

\section{Introduction}

Solar radiation per unit area $\left(\mathrm{W} \cdot \mathrm{m}^{-2}\right)$, or irradiance, is an essential variable for several applications including renewable energies, agriculture, health, engineering, and architecture. Two main methods have been used to obtain surface solar radiation, surface monitoring by instruments and that based on satellite images [1-4]. Both methods can have a high ability to provide radiometric data but with several technical limitations. Solar irradiance based on a planar surface of monitoring the surface instrument has the disadvantage of being expensive to implement because pyranometers are used. On the other hand, the solar irradiance method based on satellite images presents technical limitations as it is incapable of providing real-time data [1].

The pyranometer is a high-precision instrument dedicated to measuring solar radiation flux density on a horizontal surface based on a thermopile sensor or silicon semiconductor (Si). The two types of pyranometers differ in spectral sensitivity, time response and implementation cost [2-4]. Pyranometers based on thermopiles have a spectral sensitivity 
of between $300 \mathrm{~nm}$ and $2800 \mathrm{~nm}$ with a time response higher than $10 \mathrm{~s}$ and a cost that can surpass USD 10,000. Pyranometers based on silicon semiconductors have a selective spectral sensitivity from $350 \mathrm{~nm}$ and $1100 \mathrm{~nm}$ with a time response of $10 \mu$ s and lower cost [5]. However, semiconductor-based pyranometers require a significant investment to implement and expand radiometric monitoring networks. In Brazil, the cost of implementing an essential infrastructure for monitoring solar irradiation has become quite limited for the national radiometric network, affecting the understanding of the behavior and availability of these crucial environmental data. The implementation cost of solar irradiation measurement systems has imposed restrictions as it is a point value [1,5-10].

The development of systems for the continuous measurement of solar irradiation has been increasingly recurrent. Nwankwo et al. [11] developed a pyranometer based on Si semiconductors. The proposed system had minimal hardware and was based on a digital multimeter. The irradiance was determined using calibration factors with no data transmission. Rus-Casas et al. [1] presented an electronic device capable of measuring solar radiation using Internet of Things (IoT) concepts to transmit the data. The developed system was aimed at photovoltaic applications, measuring the diffuse and global components of solar radiation. This system utilized low-cost microcontrollers to obtain global solar radiation values from sensors and transmit them to cloud-based data.

Martínez et al. [5] developed a pyranometer based on Si semiconductors with a spectral sensitivity in the range of 400 to $750 \mathrm{~nm}$. The system featured hardware based on a programmable interface controller (PIC) featuring a heating system, communication via the serial port for the transmission of the collected data and level adjustment. In order to correct the effect of the movement of the solar disk, a diffuser made of polytetrafluoroethylene (PTFE) was implemented. Balan et al. [12] developed a system to monitor solar radiation based on a microcontroller and data transmission via a wireless network. The transmitted data was stored in a structured database, allowing immediate consultation.

Thus, commercial solutions that combine measurement irradiation with wireless data transfer technology are scarce and expensive, leading to the development of systems that combine the continuous monitoring of surface solar irradiation with the IoT, thus reducing cost and uncertainty $[13,14]$. The IoT corresponds with the set of objects, generically treated as "things", with software, sensors, and protocols to connect to the world wide web, allowing a remote interaction with the physical environment [15-17]. The IoT enables intelligent devices to communicate with high latency wireless networks, offering reliability, security, and privacy of the transmitted data [18-20].

This study presents the development, implementation, and validation of the preliminary results for a system that allows a remote measurement of surface solar irradiation in real-time. The proposed system uses IoT technology to safely enable low-cost, intelligent, and reliable measures and provide radiometric data from multiple web platforms. The study's contribution is to present a temperature-insensitive smart electronic device that can send data to web interfaces and reduce the pyranometers based on the cost of semiconductor junctions.

\section{System Architecture}

\subsection{Conceptual Design}

The proposed system for the real-time measurement of surface solar irradiation is presented in Figure 1. It comprises an irradiation sensor, an indicator for status/alert messages, a signal conditioning circuit, and a low-consuming energy microcontroller. The microcontroller Tensilica Xtensa LX106 implements the MQTT (message queuing telemetry transport) protocol for data transmission. 


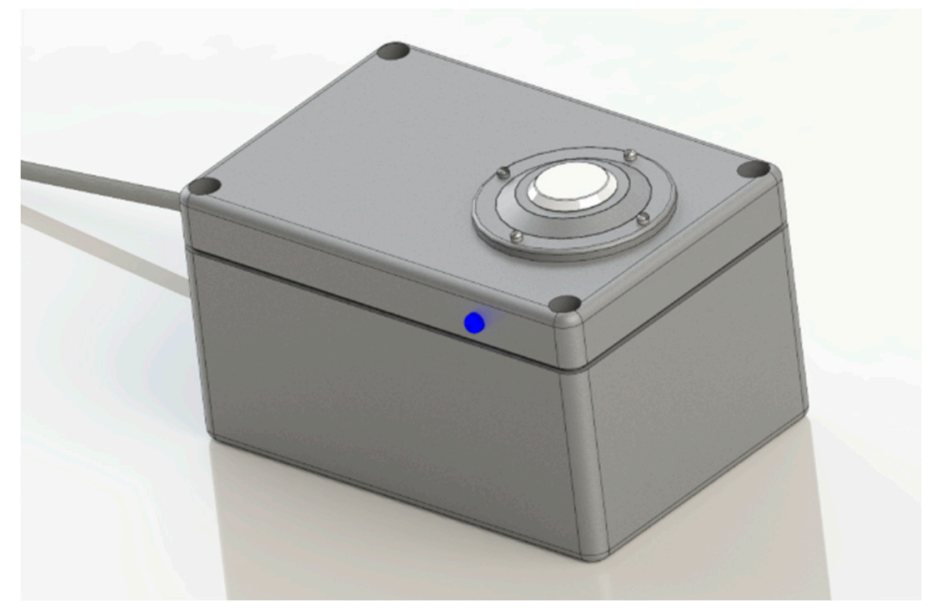

Figure 1. Concept developed in a virtual environment for the wireless solar irradiation monitoring system at the surface.

The prototype has a rectangular external body $125 \mathrm{~mm}$ long $\times 85 \mathrm{~mm}$ wide $\times 70 \mathrm{~mm}$ high) and $3 \mathrm{~mm}$ thick polyethylene. The case has layers of acrylic paint to increase the resistance to ultraviolet (UV) radiation. It has hygroscopic salt inside to prevent condensate formation and has an adjustable base allowing the system to be installed on pedestals or horizontal surfaces.

Figure 2 represents the hardware structure of the proposed system. The principle of the operation and resources inherent to the prototype system will be addressed in Sections 2.2-2.4.

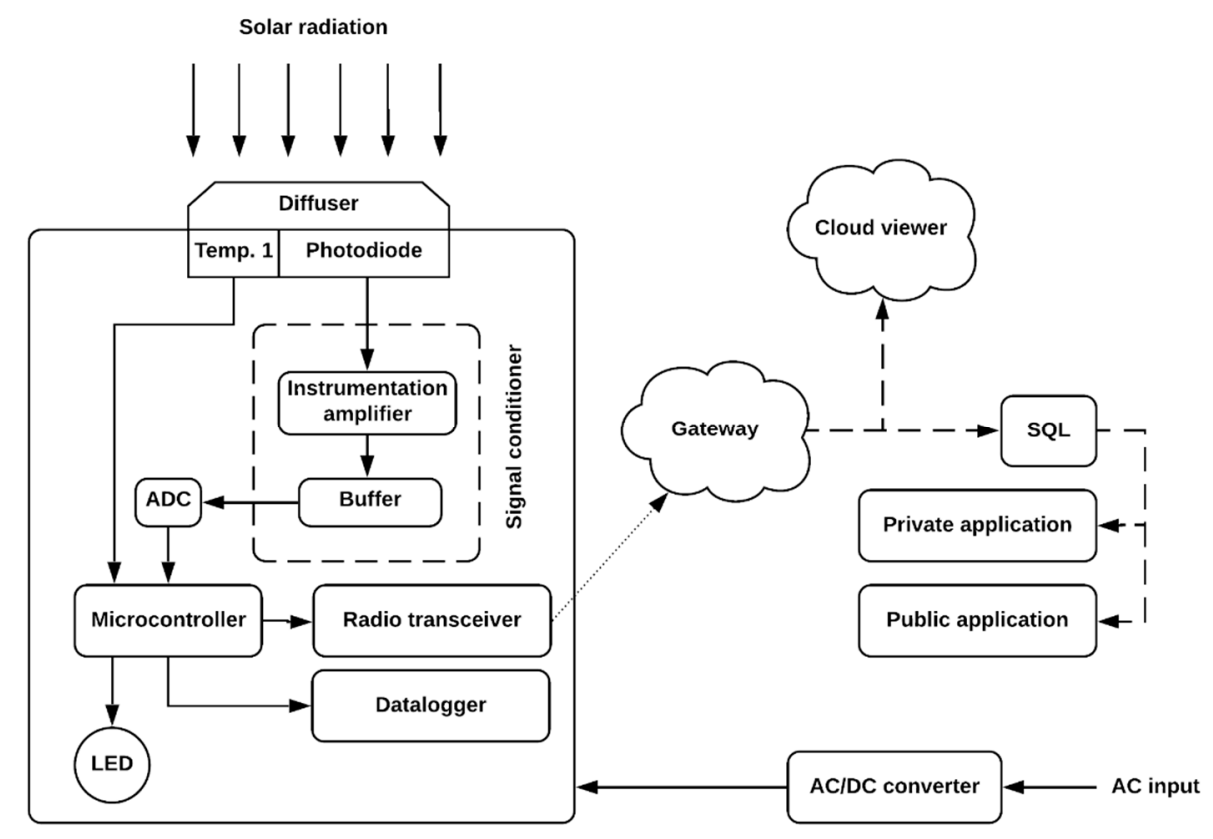

Figure 2. Block diagram of the wireless system for monitoring solar irradiation at the surface.

\subsection{Hardware}

The electronic hardware is composed of a microcontroller, a signal conditioning circuit, and an irradiation sensor. The microcontroller runs the developed firmware to control all processes necessary to measure surface solar irradiation with an autonomous operation and self-supervision. 


\subsubsection{Radiation Sensor}

The radiation sensor (Figure 3 ) consists of a diffuser (A), a photodiode (B), a temperature sensor $(C)$ and a housing $(D)$ that contains all of the elements mentioned.

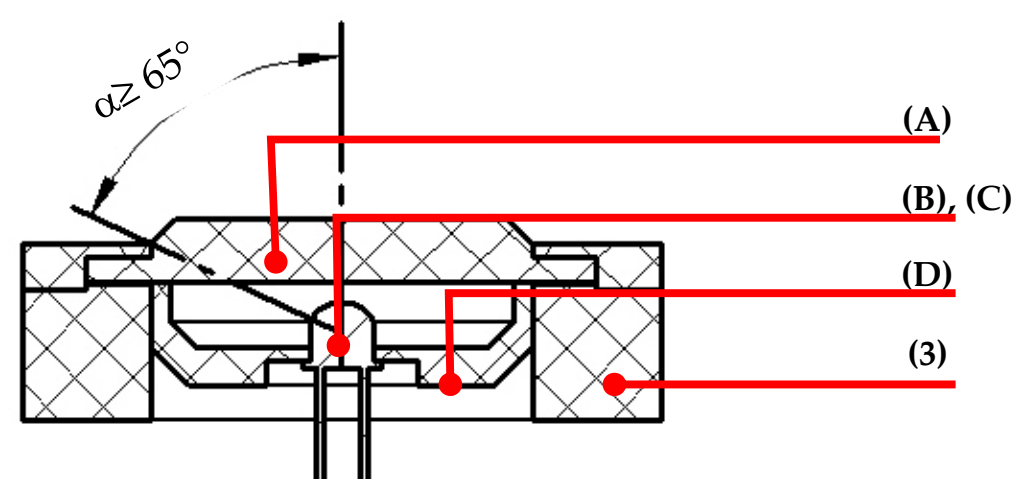

Figure 3. Sectional representation of the irradiation sensor architecture.

The diffuser $(\mathrm{A})$ is located at the top of the prototype, acting as a directional optical window made of polytetrafluoroethylene (PTFE). The selection of the material was based on the optical properties of constant transmittance for the entire range of spectral sensitivity of the photodiode and resistance to UV radiation, providing a response to the displacement of light with losses of less than $5 \%$ and a dimensional stability for the chosen geometry [5,21-23]. The diffuser has beveled edges at $45^{\circ}$ and a diameter that allows the photodiode a semi-angle of sensitivity $(\alpha)$ greater than $65^{\circ}$, offsetting the displacement of the light rays at low altitudes [5,22].

The radiation sensor is made up of a Vishay BPW34 model photodiode. It was chosen based on the characteristics listed in Table 1 from a technical analysis of the most popular commercial models.

Table 1. Basic features of bwp34 photodiode [24].

\begin{tabular}{cc}
\hline Technical Feature & Values \\
\hline Radiation-sensitive area $\left(\mathrm{mm}^{2}\right)$ & 7.5 \\
Sensitivity $\left(\mathrm{A} \cdot \mathrm{W}^{-1}\right)$ & 0.62 \\
Noise equivalent power $\left(\mathrm{W} \cdot \mathrm{Hz}^{-1 / 2}\right)$ & $4 \times 10^{-14}$ \\
Spectral sensitivity $(\mathrm{nm})$ & 380 to 1400 \\
Response time $(\mathrm{ms})$ & 0.1 \\
Opening angle $\left({ }^{\circ}\right)$ & \pm 65 \\
Temperature coefficient $\left(\mathrm{mV} \cdot \mathrm{K}^{-1}\right)$ & -2.6 \\
Dimensions $(\mathrm{mm})$ & $5.4 \times 4.3 \times 3.2$ \\
Typical operating temperature $\left({ }^{\circ} \mathrm{C}\right)$ & 25 \\
\hline
\end{tabular}

The photodiode output signal $\left(\Delta \mathrm{I}_{\mathrm{ph}}\right)$ presents the relationship between the incident surface solar irradiance $(R)$, the active surface area $(A)$ and the photodiode's responsiveness $(\beta)$. The estimation of the output signal is obtained by Equation (1), based on the irradiance of $1000 \mathrm{~W} \cdot \mathrm{m}^{-2}$ and the photodiode characteristics listed in Table 1.

$$
\Delta \mathrm{I}_{\mathrm{ph}}=\mathrm{R} \cdot \mathrm{A} \cdot \beta
$$

\subsubsection{Signal Conditioning Circuit}

The signal conditioning circuit (Figure 4$)$ converts the photodiode output signal $\left(\Delta \mathrm{I}_{\mathrm{ph}}\right)$ into a proportional voltage signal $\left(\mathrm{V}_{\text {out }}\right)$. An instrumentation amplifier circuit implemented the conditioning circuit (U1-U3) and buffer (U4). The buffer (U4) provides electric isolation from the photodiode and keeps the output signal $\mathrm{V}_{\text {out }}$ stable $[25,26]$. 


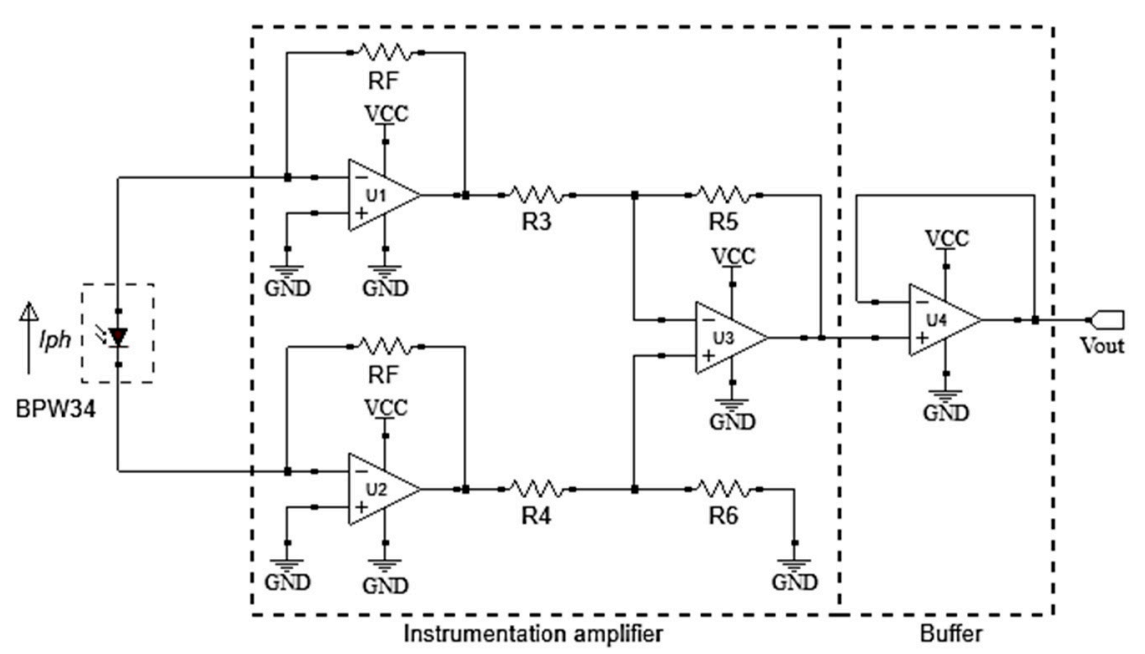

Figure 4. Architecture of the signal conditioning circuit.

The topology of the instrumentation amplifier was modified, turning it into a combination of two negative feedback trans-impedance amplifiers (U1 and U2) connected to a differential amplifier (U3). The topology obtained allows the polarization current of the photodiode $\left(\Delta \mathrm{I}_{\mathrm{ph}}\right)$ to flow simultaneously in the two feedback resistors (RF). Thus, the output voltage $\left(\mathrm{V}_{\text {out }}\right)$ is proportional to the product between the photodiode current $\left(\Delta \mathrm{I}_{\mathrm{ph}}\right)$ and the resistors RF, R6 and R4. Equation (2) presents the relationship between the output voltage $\left(\mathrm{V}_{\text {out }}\right)$ and photodiode current $\left(\Delta \mathrm{I}_{\mathrm{ph}}\right)$.

$$
\mathrm{V}_{\text {out }}=\Delta \mathrm{I}_{\mathrm{ph}} \cdot 2 \cdot \mathrm{RF} \cdot\left(\frac{\mathrm{R}_{6}}{\mathrm{R}_{4}}\right) .
$$

Figure 5 shows the relationship between $V_{\text {out }}$ and $\Delta \mathrm{I}_{\mathrm{ph}}$. The values of RF, R4 and R6 resistances are $22 \Omega, 4.7 \mathrm{k} \Omega$ and $6.8 \mathrm{k} \Omega$, respectively. The resistor's values were determined based on the estimation of $\Delta \mathrm{I}_{\mathrm{ph}}$ necessary to obtain a maximum output voltage of $400 \mathrm{mV}$ $\left(\mathrm{V}_{\text {out }}\right)$.

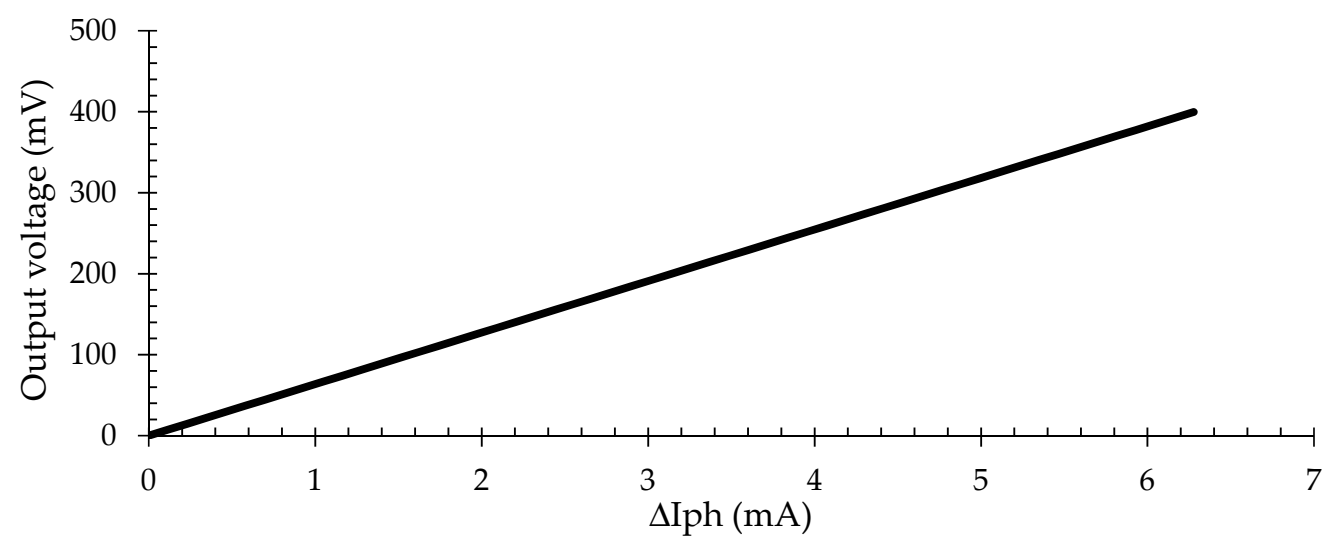

Figure 5. Output voltage $(\mathrm{mV})$ behavior for the signal conditioning circuit.

\subsubsection{Microcontroller}

A low-energy microcontroller ESP8266 with a Tensilica Xtensa LX106 32-bit processor with a maximum clock of $160 \mathrm{MHz}$ is used to implement the proposed solution. It presents the following resources: $64 \mathrm{~KB}$ RAM, $512 \mathrm{~KB}$ flash memory, GPIOs connectors, an internal 10-bit resolution analog-to-digital converter (ADC), $3.22 \mathrm{mV}$ sensitivity and a maximum sampling rate of $80 \mathrm{kHz}$. The microcontroller's inputs and outputs are designed for operating at voltages from $0 \mathrm{~V}$ to $3.3 \mathrm{~V}$. The system is connected to an external $18 \mathrm{~W} \mathrm{DC}$ power supply. 
The microcontroller (Figure 6) has an integrated radio transceiver integrated with the IEEE $802.11 \mathrm{~b} / \mathrm{g} / \mathrm{n}$ standard for a connection speed up to $2.4 \mathrm{GHz}$. The radio transceiver operates with a built-in ShockBurst ${ }^{\mathrm{TM}}$ protocol, allowing the microcontroller to maintain wireless connections to TCP/IP networks. In addition, it supports WPA/WPA2 safe communication and sets up a connection with authentication or communication encrypted by a token $[27,28]$.

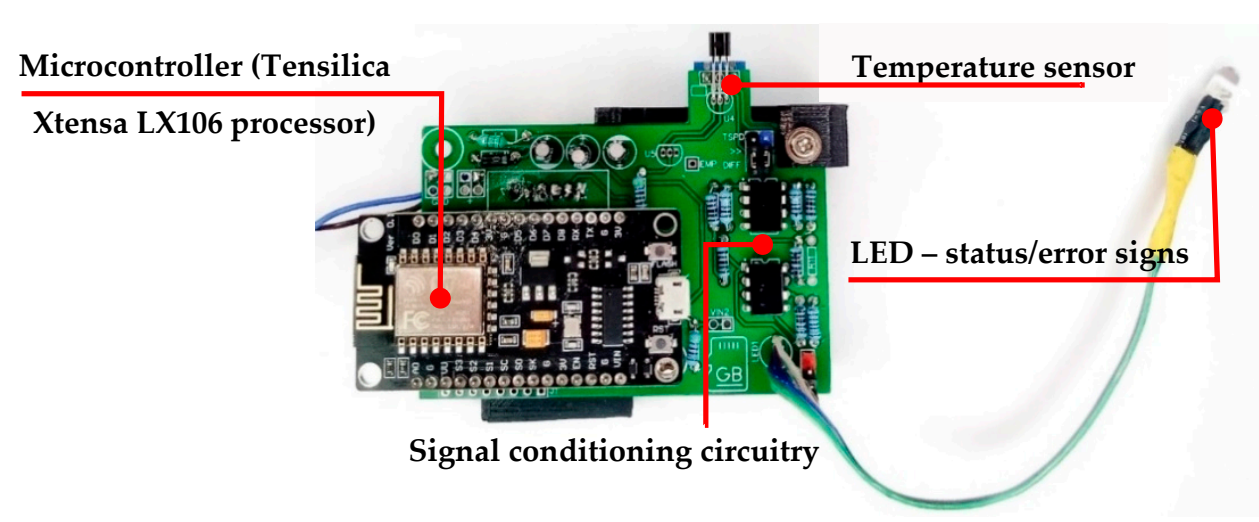

Figure 6. Prototype hardware for the real-time measurement of surface solar radiation.

\subsubsection{Data Storage}

The hardware presents a datalogger that stores the collected data in a removable flash memory. The datalogger has a storage capacity of $4 \mathrm{~GB}$, allowing for consecutive data storage up to four years or $10^{6}$ cycles. The datalogger prevents lost data when the communication between the microcontroller and the wireless network is interrupted. The output files use extensions .txt or .csv with an ASCII writing pattern stored at $60 \mathrm{~s}$ intervals. The stored values correspond with the voltage level $(\mathrm{mV})$, radiation level $\left(\mathrm{W} \cdot \mathrm{m}^{-2}\right)$, sensor temperature $\left({ }^{\circ} \mathrm{C}\right)$ and alerts generated by the microcontroller.

\subsection{Firmware}

In order to perform a system operation to regulate surface radiation and data storage, the firmware was developed in $\mathrm{C}++$ language and is shown in Figure 7. The firmware controls and executes all of the processes essential for a hardware operation (threads). The threads can generate signal statuses or alerts by a visual indication of an RGB LED. The signal statuses or alerts are listed in Table 2.

Table 2. Identification of alerts issued.

\begin{tabular}{cccc}
\hline Alert & Meaning & \multicolumn{2}{c}{ Associated Color } \\
\hline 1 & Firmware startup & $\bigcirc$ & Green \\
2 & Startup errors (datalogger) & $\bigcirc$ & Turquoise blue \\
3 & Datalogger-insufficient storage volume & $\bigcirc$ & Yellow \\
4 & Wireless connection failure & $\bigcirc$ & Pink \\
5 & Datalogger or network connection failed & $\bigcirc$ & Orange \\
6 & Sensor reading failure & $\bigcirc$ & White \\
7 & Full data transmission & $\bigcirc$ & Blue \\
8 & Data transmission failure & $\bigcirc$ & Red \\
\hline
\end{tabular}




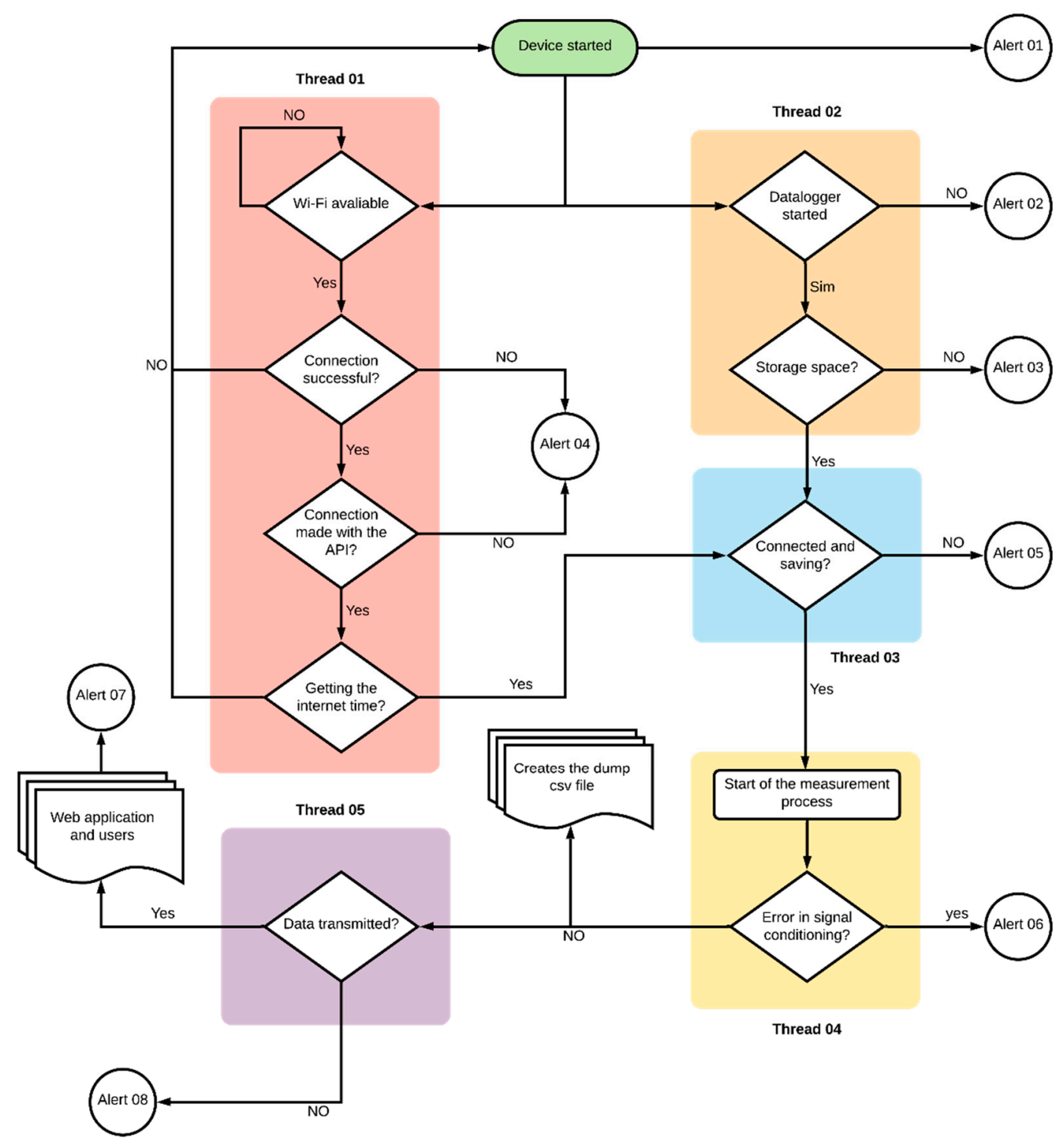

Figure 7. Flowchart of the identification of the firmware blocks and errors.

Thread 01 is responsible for the device's startup and communication with local internet networks. It identifies available wireless networks within $50 \mathrm{~m}$ of the device, connects the device and synchronizes it with the server. Thread 02 verifies the operation and availability of data storage space in the datalogger. Thread 03 is a self-supervising mechanism, checking the connection between the device and the wireless network with a data storage capacity while Threads 04 and 05 occur. Thread 04 is responsible for the process of reading the signal from the conditioning circuit, obtaining the irradiation value, and requesting data transmission. Thread 05 transmits data directly to the server even on limited networks.

\subsubsection{Data Transmission Protocol}

The protocol implemented for data transmission to the server is the MQTT, a flexible network model used to send information between devices and servers. This protocol is compatible with most network protocols, allowing for orderly connections without data loss on low-power devices and wireless networks with a limited speed and high latency [29-36].

\subsubsection{Adjust of Radiation Sensor Output}

The output signal of the conditioning circuit $\left(\mathrm{V}_{\text {out }}\right)$ can be affected by the photodiode temperature $(\mathrm{T})$ and by the average trajectory of the solar disk. In order to mitigate 
those effects, it has implemented correction functions based on the methodologies of King et al. [36], Kern [37] and Myers [38] and Mcarthur et al. [39].

A temperature sensor (DS18B20) was used to correct the influence of temperature $\left({ }^{\circ} \mathrm{C}\right)$ on the photodiode current output, keeping readings stable during the operation. A linear and dimensionless correction function $f(T)$ (Equation (3)) is applied. The coefficients $\theta$ and $\tau$ are $8 \times 10^{-3}{ }^{\circ} \mathrm{C}^{-1}$ and 0.998 , respectively.

$$
f(T)=\theta \cdot T\left({ }^{\circ} \mathrm{C}\right)+\tau .
$$

The function for the trajectory correction of the solar disk was based on Fanner et al. [40] and Brooks [41] (Equation (4)). It is modeled as a cosine function that uses the local time when the device is installed and is valid for the active photoperiod with time (h) in the range from $330 \mathrm{~min}$ to $1050 \mathrm{~min}$. The coefficients used in function $g(h)$ are $\gamma=2.6762$ and $\varpi=3.9 \times 10^{-3} \mathrm{~min}^{-1}$, respectively. The corrected voltage of the conditioning circuit ( $\mathrm{V}_{\text {out_corr }}$ ) is expressed by Equation (5).

$$
\begin{aligned}
& g(h)=(\cos (\gamma-\omega h[\min ]))^{-1} \\
& \mathrm{~V}_{\text {out_corr }}[\mathrm{mV}]=\frac{V[\mathrm{mV}]}{g(h) \cdot f(T)} \rightarrow \mathrm{V}_{\text {out_corr }}[\mathrm{mV}]=\frac{V[\mathrm{mV}]}{\theta T\left[{ }^{\circ} \mathrm{C}\right]+\tau} \cdot \cos (\gamma-\omega h[\mathrm{~min}]) .
\end{aligned}
$$

\subsection{Data Visualization System}

Figure 8 shows the user interface developed for data visualization. It shows the geographic location of the measurement, sensor number, time data, instantaneous surface irradiation value, the time elapsed since the last update and the download option. The user interface is available at https:/ / www.radiacaoagora.tk/, (accessed on 27 April 2021) which uses an API of the platform ThingSpeak. A cloud computing system performs the procedures for collecting, processing, storing, exhibiting, and automatically exporting the measured data to the website and users.

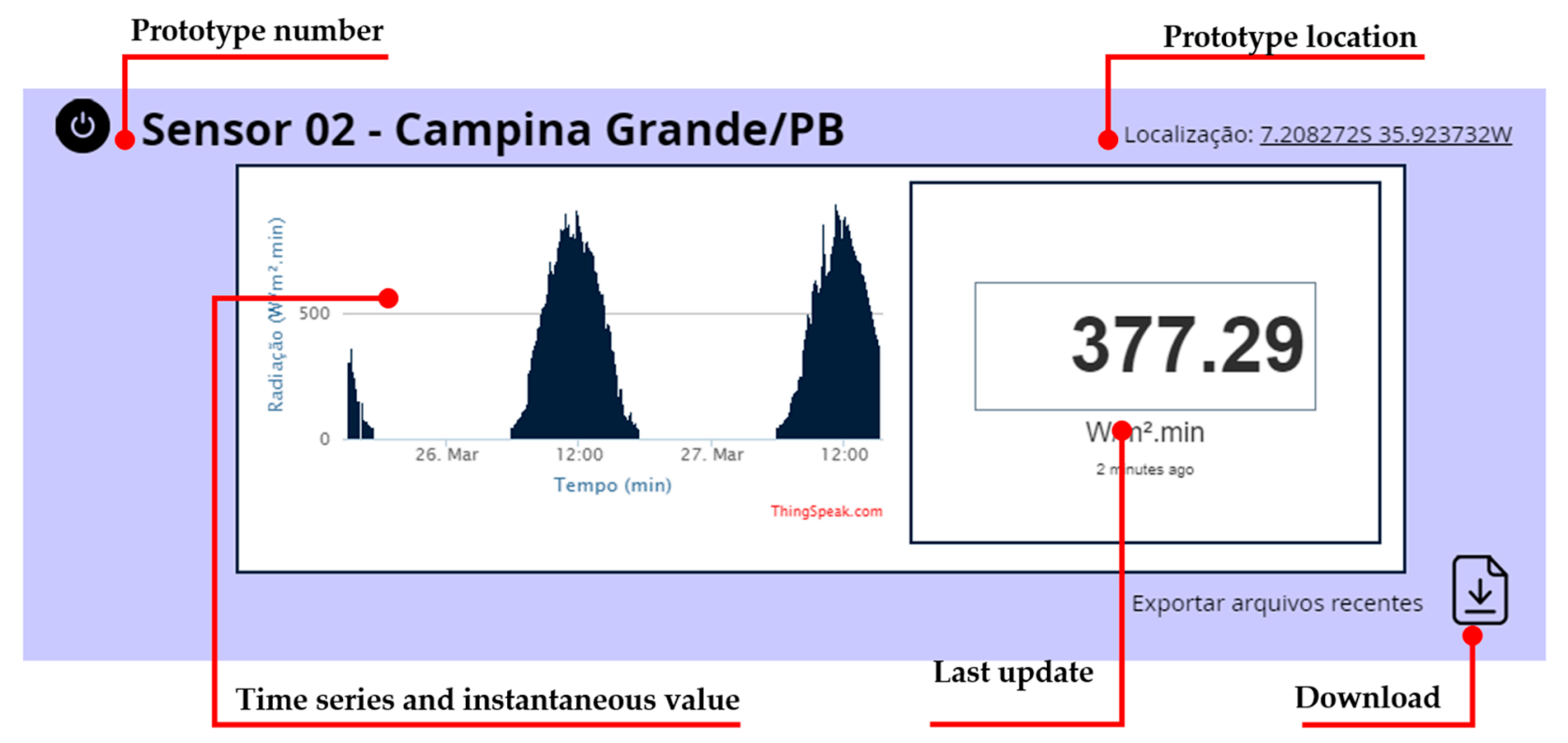

Figure 8. Data visualization web interface with its principal information.

\subsection{Prototypes}

The experiments were carried out with two prototypes (P01 and P02), which were calibrated and tested in Campina Grande/Paraíba in the northeast region of Brazil (NEB) at $512 \mathrm{~m}$ above sea level with average annual temperatures of $23.5^{\circ} \mathrm{C}$ and annual rainfall 
between 300 and $1200 \mathrm{~mm}$ [42-44]. The prototypes were installed in an urban area, $3 \mathrm{~km}$ away from the reference weather station (Figure 9). The installation of the devices maintained a maximum inclination of $2.0^{\circ} \mathrm{C}$ in relation to the horizontal plane and was free of shading on the devices.
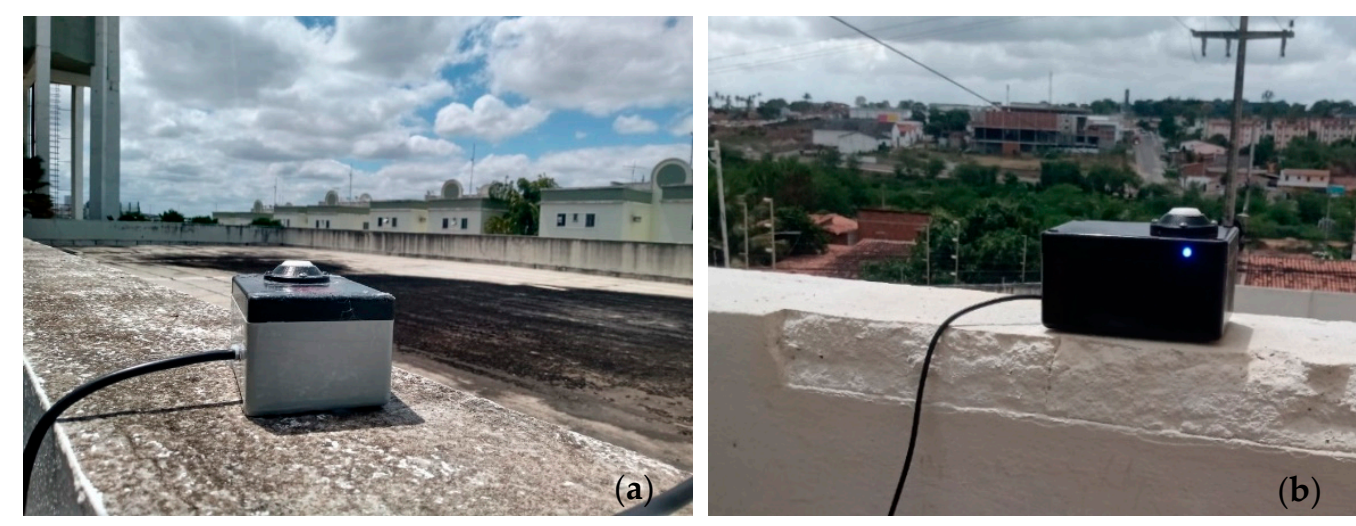

Figure 9. Prototypes installed in Campina Grande, Brazil: (a) P01, (b) P02.

\subsection{Calibration}

The calibration of the prototypes was carried out from 21-25 October 2019. The calibration procedure for the prototypes followed the ISO 9847 standard using a standard Lambrecht secondary pyrometer, model 16106, for a data acquisition rate of $1 \mathrm{~min}$. The calibration occurred at the Brazilian National Institute of the Semi-Arid (INSA) facilities, Campina Grande, Brazil.

The data processing in the calibration data employed a K-means clustering algorithm [45], which analyzed and modeled the collected data, minimizing dispersion effects because of a variation in the atmospheric transmittance and synchronization of the data acquisition time between the prototype and the reference pyranometer.

\subsection{Data and Experimental Area}

A weather station's official data of surface solar irradiation were obtained at the Brazilian Agricultural Research Company (Embrapa-Algodão). The weather station has a class 2 standard pyranometer connected to the Brazilian National Institute of Meteorology (INMet) and a unit of surface solar irradiation given in $\mathrm{kJ} \cdot \mathrm{m}^{-2}$.

\subsection{Data Analysis}

A data analysis compared the values provided by the prototypes and the reference data from Embrapa/INMet, which were analyzed using the statistical techniques of Reda [46], Miot [47], Diniz [48] and Tiepolo [49]. Data processing followed the statistical parameters of coefficients of determination $\left(R^{2}\right)$, Pearson's correlation coefficient $(r)$, mean absolute percentage error (MAPE), root mean square of relative errors (rRMS), index of agreement (d) of Willmott et al. [50] and confidence index (c). In order to classify the parameters, Tables 3-5 were used as references. In addition, the relative frequencies of radiometric divergences were analyzed and presented as histograms and a probability density function (PDF). 
Table 3. Pearson correlation coefficient performance classification (r) [47].

\begin{tabular}{cc}
\hline Pearson Correlation Coefficient (r) & Classification \\
\hline $0.91-0.99$ & Almost perfect \\
$0.71-0.90$ & Too high \\
$0.51-0.70$ & High \\
$0.31-0.50$ & Moderate \\
$0.11-0.30$ & Low \\
$<0.10$ & Too low \\
\hline
\end{tabular}

Table 4. Performance rating for the confidence index (c) [47].

\begin{tabular}{cc}
\hline Confidence Index (c) & Classification \\
\hline$>0.85$ & Great \\
$0.76-0.85$ & Very good \\
$0.66-0.75$ & Good \\
$0.61-0.65$ & Median \\
$0.51-0.60$ & Poor \\
$0.41-0.50$ & Bad \\
$<0.40$ & Unsatisfactory \\
\hline
\end{tabular}

Table 5. Performance classification for the quadratic root of relative errors (rRMS) [51].

\begin{tabular}{cc}
\hline Quadratic Root of Relative Errors (rRMS) & Classification \\
\hline$>0.30$ & Poor \\
$0.20-0.30$ & Acceptable \\
$0.10-0.20$ & Good \\
$<0.10$ & Excellent \\
\hline
\end{tabular}

\section{Results and Discussion}

\subsection{Sensor Output Signal Behavior}

Figure 10 shows the voltage measurements $(\mathrm{mV})$ provided by prototypes P01 and P02 in the conditions of low (insolation less than $4 \mathrm{~h}$ ), medium (insolation between 4 and $8 \mathrm{~h}$ ) and high atmospheric transmittance (insolation greater than $8 \mathrm{~h}$ ).
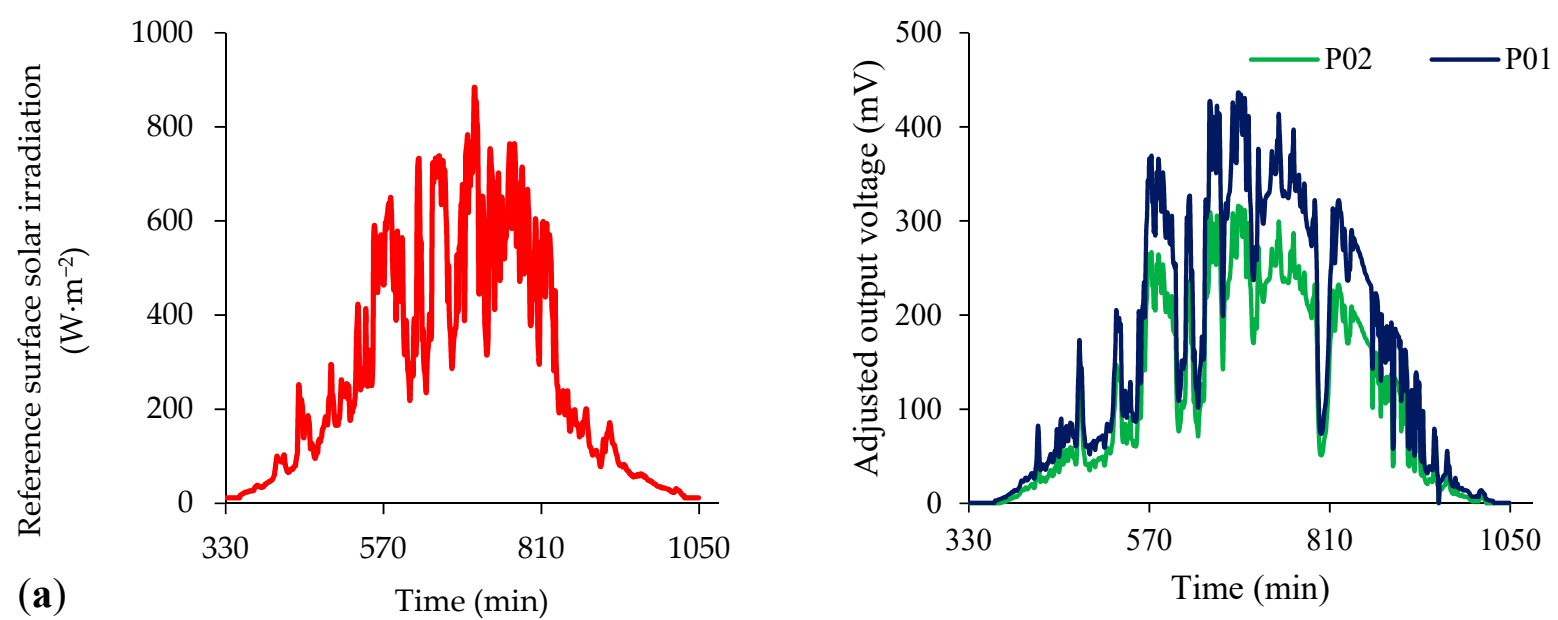

Figure 10. Cont. 

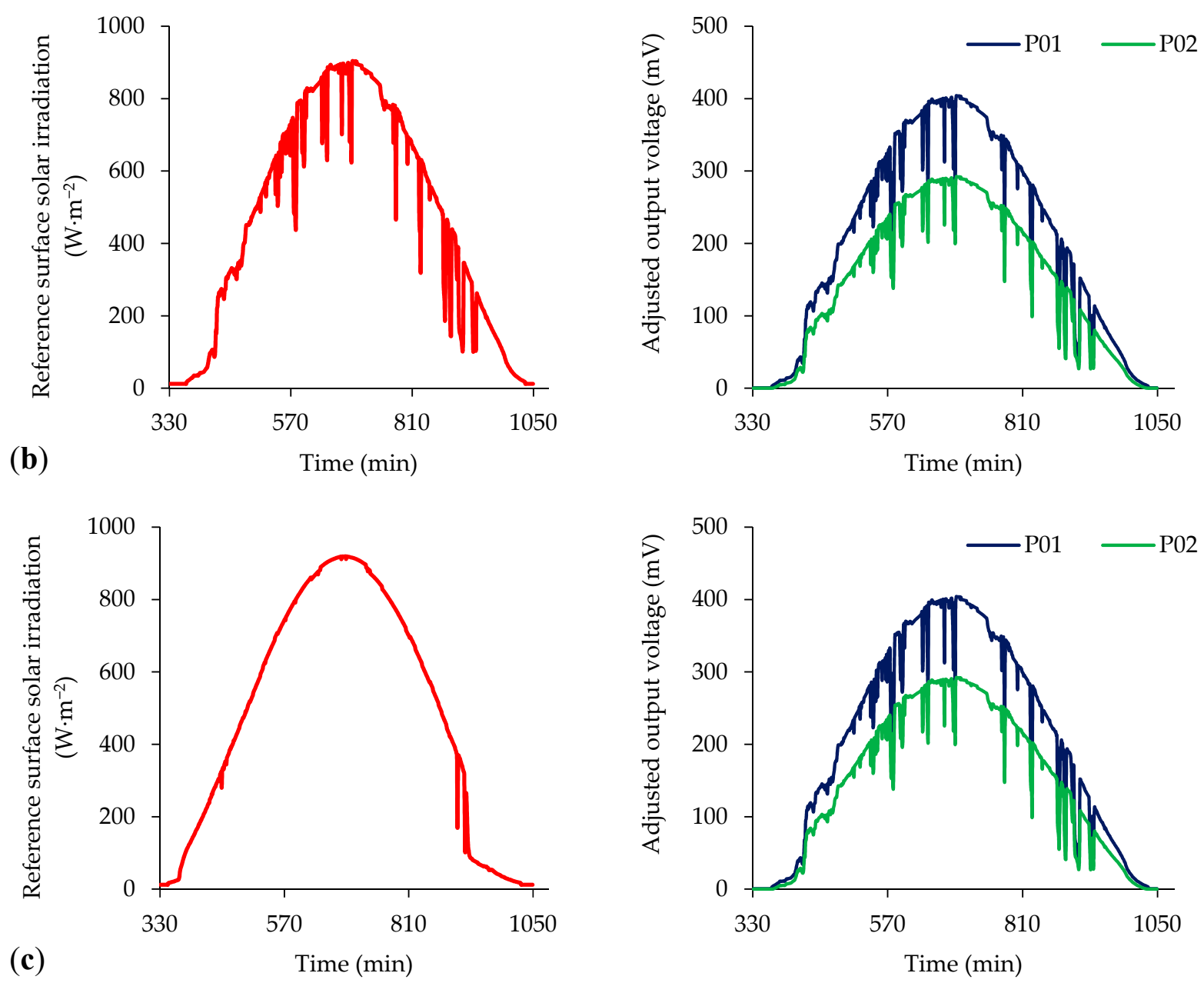

Figure 10. Reference surface solar irradiation $\left(\mathrm{W} \cdot \mathrm{m}^{-2}\right)$ and voltage $(\mathrm{mV})$ time series at a sensor output for low (a); moderate (b) and high (c) transmittance conditions.

The differences identified between the signals provided by the prototypes were due to the non-homogeneity of atmospheric phenomena within the same region, inducing the variation of readings [52]. It was observed that the behavior of the sensor voltage followed the surface solar irradiation curve at all times of the day, demonstrating that the proposed system was unaffected by variations in ambient temperature. The thermal insensitivity was caused by the real-time correction of the sensor voltage as a function of its instantaneous temperature.

\subsection{Radiation Sensor Calibration}

The data obtained during the calibration period were registered on a Cartesian plane. The $x$-axis corresponded with the system response (corrected voltage) and the $y$-axis was the value of the reference solar irradiation. At the end of the calibration period, 3200 ordered pairs were collected for each prototype. The calibration process was based on the high transmittance model. The results were treated with a k-means clustering algorithm to reduce the impact of outliers and obtain curves more representative of the data's average behavior.

Figure 11 depicts the relationship between the reference pyranometer's radiometric reading and the system response after data processing with the k-means algorithm. 

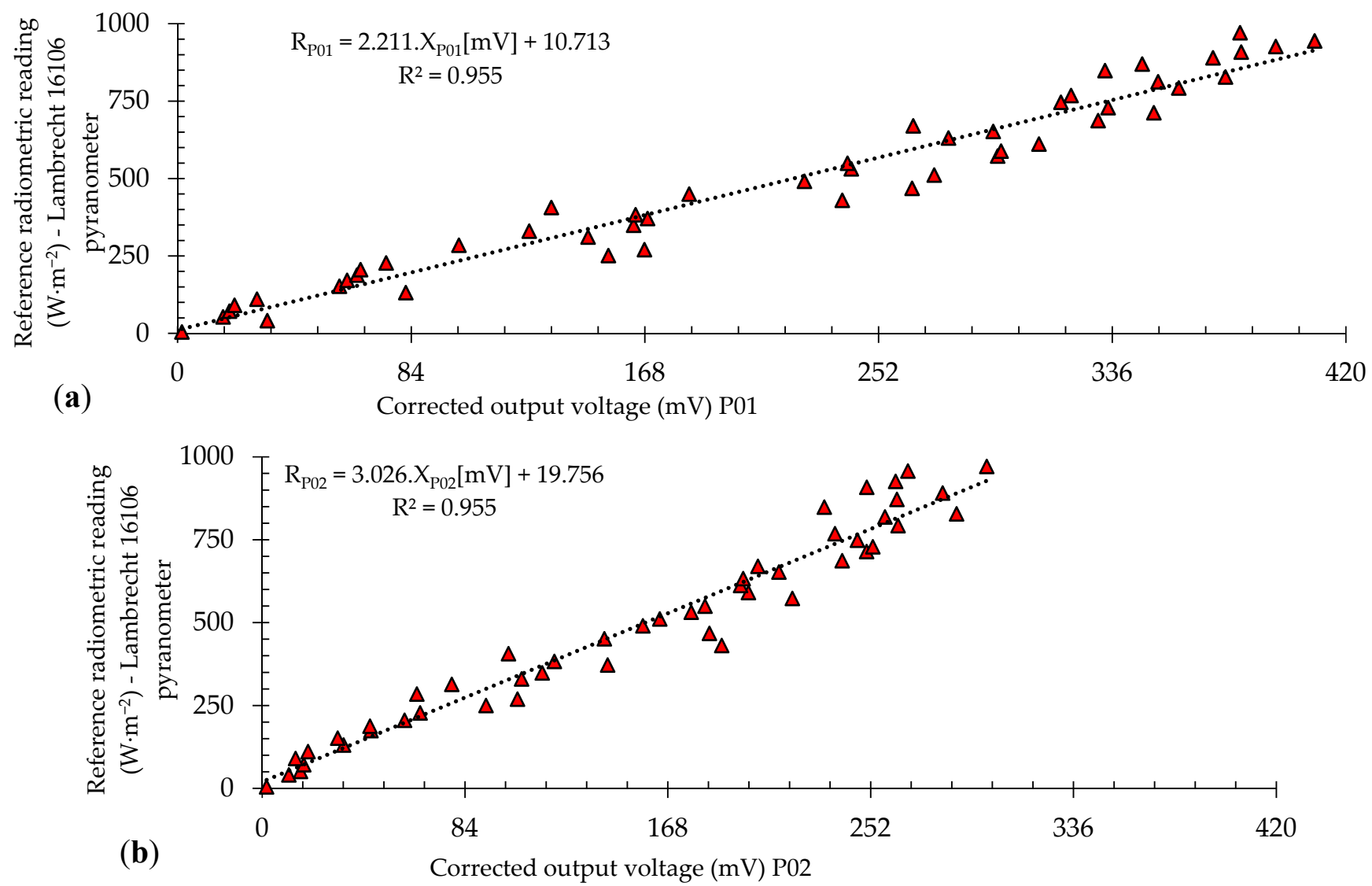

Figure 11. Solar irradiation by the reference pyranometer vs. the prototype response: (a) P01, (b) P02.

The linear regression and statistical indices were calculated to validate the process to verify the degree of agreement between the experimental and reference data. Table 6 presents a summary of the statistical analysis for prototypes P01 and P02.

Table 6. Summary of statistical indices for prototypes P01 and P02 after the calibration process.

\begin{tabular}{ccc}
\hline Metrics & Prototype P01 & Prototype P02 \\
\hline Coefficients of determination $\left(\mathrm{R}^{2}\right)$ & 0.955 & 0.955 \\
Correlation coefficients $(\mathrm{R})$ & 0.977 & 0.977 \\
Pearson coefficient $(\mathrm{r})$ & 0.977 & 0.977 \\
Agreement index $(\mathrm{d})$ & 0.953 & 0.950 \\
Confidence index $(\mathrm{c})$ & 0.932 & 0.928 \\
\hline
\end{tabular}

The classification for the statistical indices for the proposed prototypes occurred according to Tables 3 and 4, indicating that the recurrence equation provided experimental safety evidence with concise solar irradiation data according to the voltage levels. The behavior of the calibration curves was similar to that presented by Lave et al. [53] and Rus-Casas [1], which obtained a correlation coefficient (R) of approximately 0.98 .

\subsection{Solar Irradiance Analysis}

The proposed system results are presented as a time series in Figure 12. The system was tested for 200 days ( $4813 \mathrm{~h}$ ) during the year 2020. However, it shows only the first 40 days $(963 \mathrm{~h}$ ) as the pattern was repeated for the following days. 

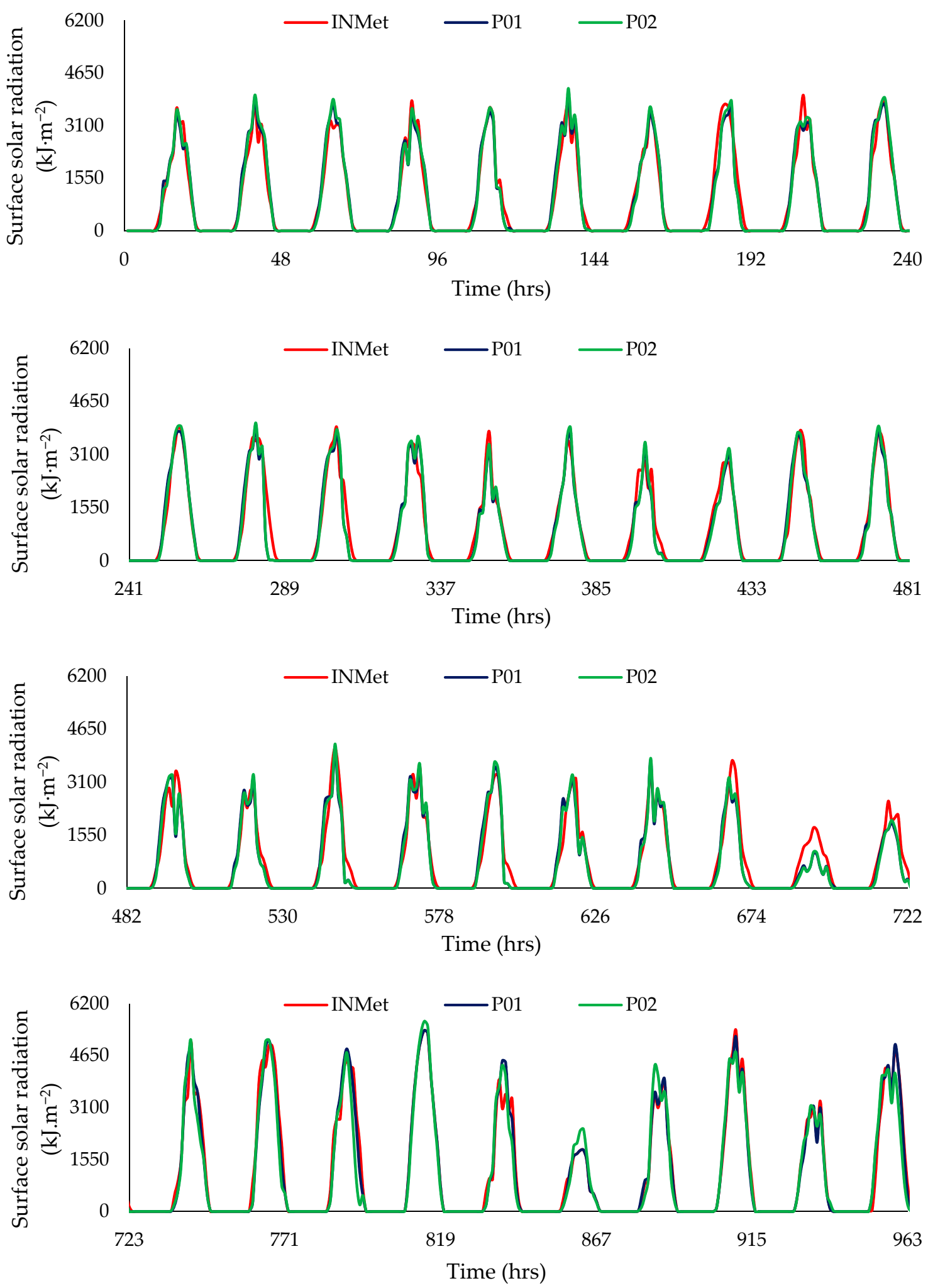

Figure 12. Comparison between the incoming surface solar radiation (INMet) and the responses of the prototypes (P01, P02) for Campina Grande, Brazil.

The comparison between the reference surface solar radiation data (INMet) and the experimental results for prototype P01 is presented in Figure 13. The $\mathrm{R}^{2}$ value for prototype P01 was 0.962 . Figure 14 compares the reference surface solar radiation data (INMet) and the experimental results of prototype P02, showing an $\mathrm{R}^{2}$ value of 0.958 . The 
values obtained for $R^{2}$ were independent of the prototype such as those obtained by Balan et al. [12] $\left(R^{2}=0.950\right)$ and by Shafa et al. [3] $\left(R^{2}=0.94\right)$.

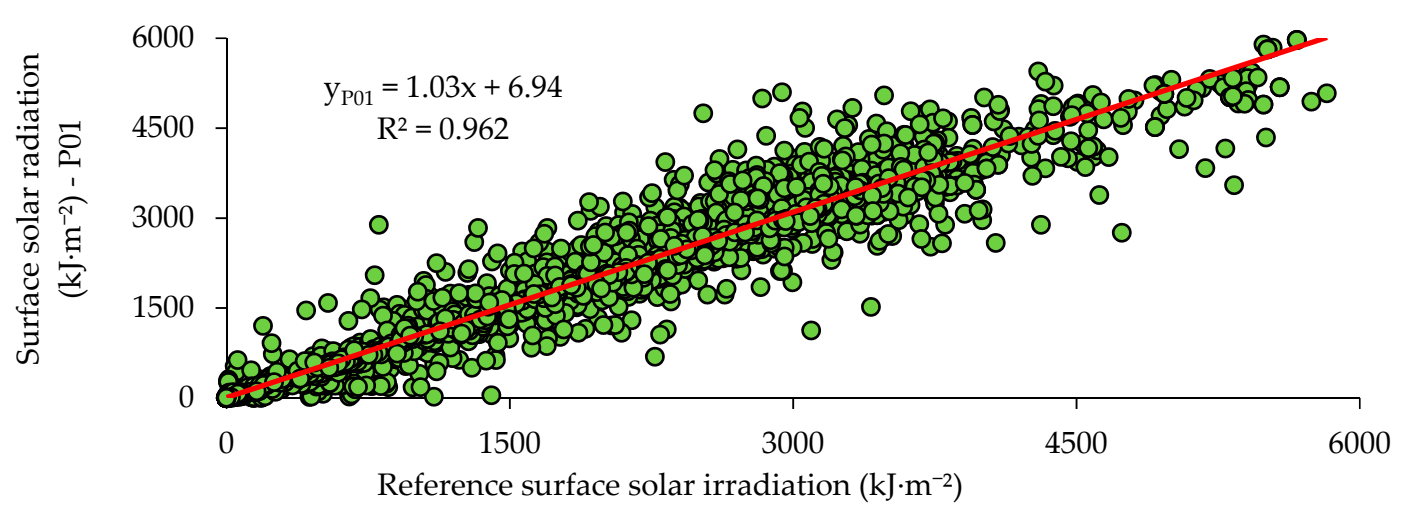

Figure 13. Scatter graph between the reference surface solar radiation (INMet) and the response of prototype P01 for Campina Grande, Brazil.

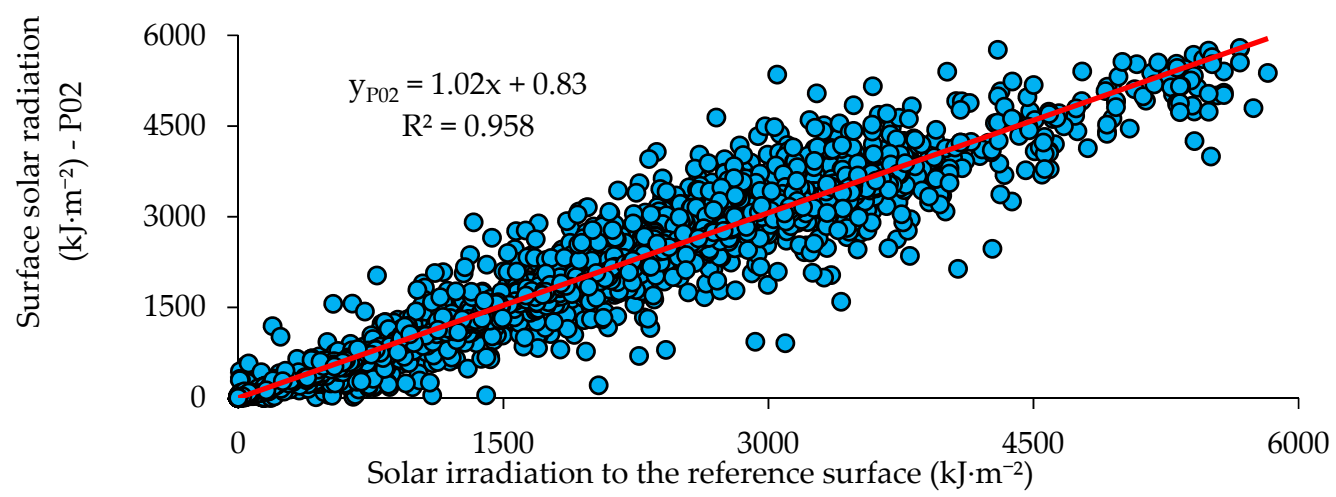

Figure 14. Scatter graph between the reference surface solar radiation (INMet) and the response of prototype P02 for Campina Grande, Brazil.

On the other hand, the mean percentage absolute error (MAPE) obtained for prototypes $\mathrm{P} 01$ and $\mathrm{P} 02$ were $-3.82 \%$ and $-2.19 \%$, respectively. The MAPE assessment considers the accuracy based on the residuals, indicating the accuracy of the forecast of the linear model. The MAPE value for the prototypes was close to the values obtained by Kim et al. [8], Dunn et al. [54] and Tohsing et al. [55] of 3.99\%, 4.60\% and 3.00\%, respectively.

When analyzing the rRMS, it was observed that prototypes P01 and P02 presented values of 0.287 and 0.294 , respectively. According to the rRMS classification (Table 6), this metric indicated an acceptable estimation of the potential for daily global radiation. High values for $\mathrm{r}, \mathrm{d}$ and $\mathrm{c}$ were also observed for prototypes P01 and P02. For prototype P01, the values were $0.981,0.960$ and 0.941 , respectively. For prototype P02, these parameters were $0.979,0.957$ and 0.937 , respectively.

Figure 15 shows the scatter graph between the measured values of prototypes P01 and $\mathrm{P} 02$.

Based on Figure 15, it could be noted that the results were concise to each other, presenting a coefficient of determination $\left(\mathrm{R}^{2}\right)$ equal to 0.987 , a MAPE of $3.25 \times 10^{-6}$, an rRMS of $3.25 \times 10^{-5}$ and a c of 0.980 . The values obtained for comparing the prototypes' responses showed that they provided the measurement of surface solar radiation in a very similar and precise manner although they presented different correlation equations. 


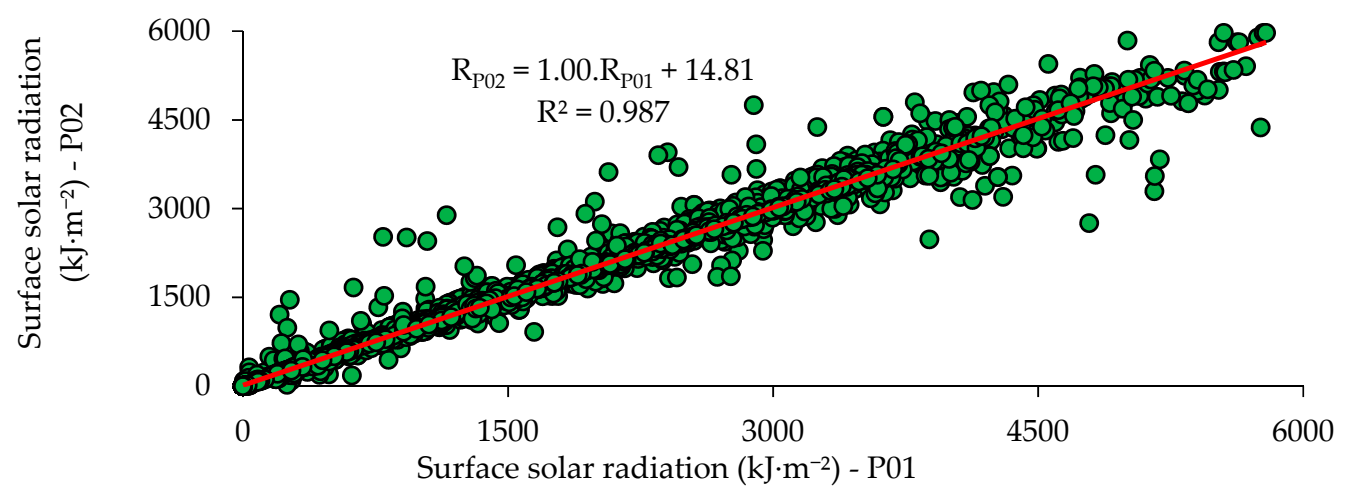

Figure 15. Scatter graph between the experimental results of prototype P01 and P02.

The PDF function was used to model the differences between the official data and the experimental measurements (Figure 16). It identified the probability that the prototype's response presented divergences within the range $\left(-500 \mathrm{~kJ} \cdot \mathrm{m}^{-2} ; 500 \mathrm{~kJ} \cdot \mathrm{m}^{-2}\right)$. Additionally, it estimated the probability of the prototypes presenting errors only within the specified range, keeping the uncertainties of measurements under those expected.
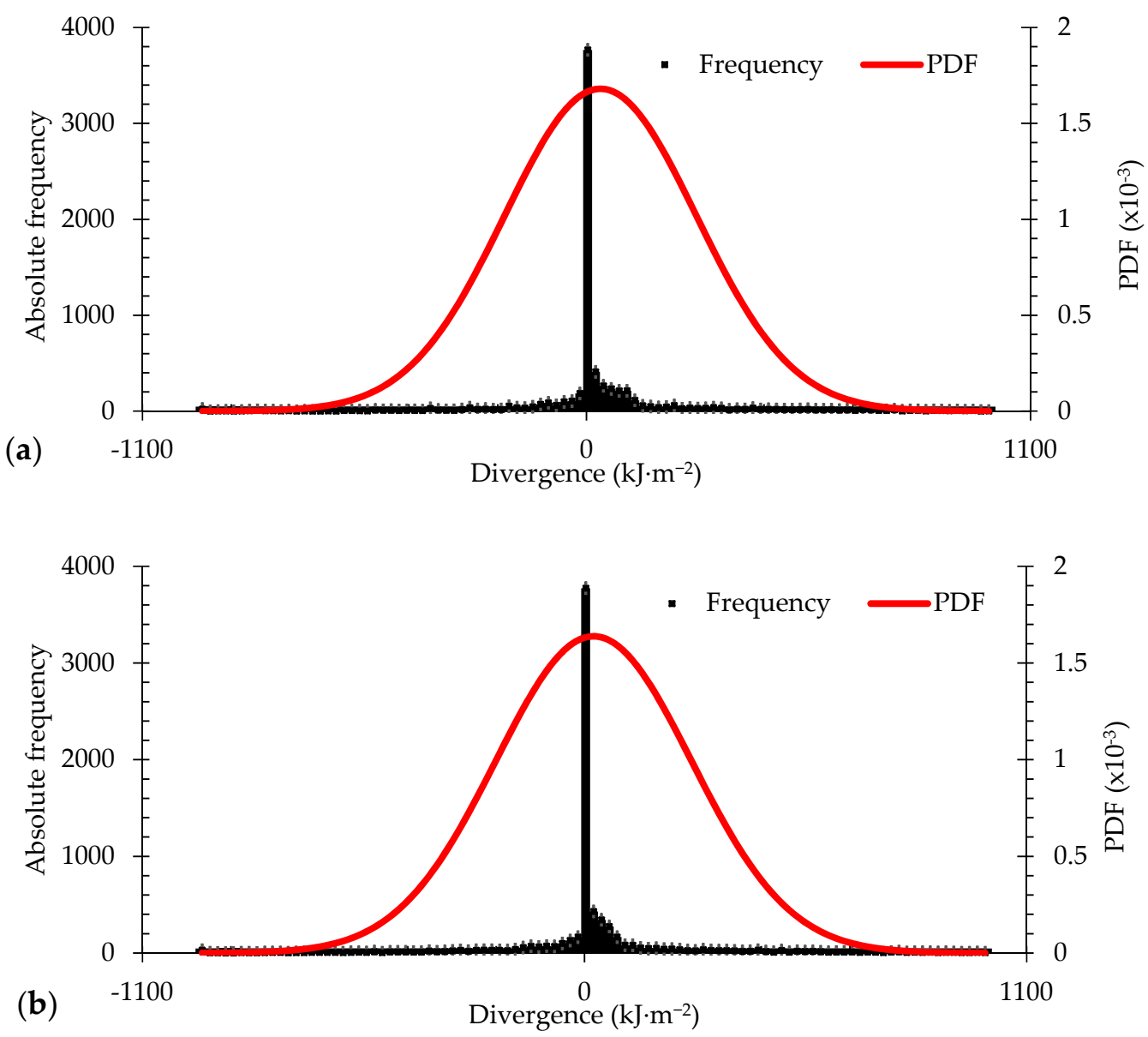

Figure 16. Relative frequency of the divergences for the prototypes: (a) P01, (b) P02.

According to Figure 16a, the frequency distribution characteristics for prototype P01 had a mean $(\mu)$ of $37.16 \mathrm{~kJ} \cdot \mathrm{m}^{-2}$ and a standard deviation $(\delta)$ of $276.92 \mathrm{~kJ} \cdot \mathrm{m}^{-2}$. The results provided by system P01 had a confidence level of $90.53 \%$ of the divergences located in the range of $\left(-500 \mathrm{~kJ} \cdot \mathrm{m}^{-2} ; 500 \mathrm{~kJ} \cdot \mathrm{m}^{-2}\right)$. On the other hand, the frequency distribution for prototype P02 (Figure 16b) presented a mean $(\mu)$ value equal to $21.29 \mathrm{~kJ} \cdot \mathrm{m}^{-2}$ and a 
standard deviation $(\delta)$ of $284.69 \mathrm{~kJ} \cdot \mathrm{m}^{-2}$. Again, the results provided by prototype $\mathrm{P} 02$ had a confidence level of $90.73 \%$ of the divergences in the range of $\left(-500 \mathrm{~kJ} \cdot \mathrm{m}^{-2} ;+500 \mathrm{~kJ} \cdot \mathrm{m}^{-2}\right)$.

\section{Conclusions}

This paper presented a new low-cost electronic system for the real-time measurement of surface solar radiation. The proposed system was composed of a solar radiation sensor, a conditioning circuit, a low-power ESP8266 microcontroller, a unit to register data (datalogger) and an internet user interface application. It was autonomous and provided remote access to surface solar radiation levels based on IoT tools. The proposed solution was composed of an electronic hardware and software tool capable of operating with minimal human intervention. The system had a power consumption of $5 \mathrm{~W} \cdot \mathrm{h}$, a mass of $400 \mathrm{~g}$ and an estimated cost of USD 200.

The proposed system was validated with experimental tests comparing the results with those provided by INMet for Campina Grande, Brazil. The experimental tests, carried out in areas with wireless network availability, indicated that the device provided irradiation levels with an accuracy greater than $96.0 \%$ and a confidence level greater than $90 \%$. It showed an estimated error of $\pm 500 \mathrm{~kJ} \cdot \mathrm{m}^{-2}$, equivalent to $138.89 \mathrm{~W} \cdot \mathrm{m}^{-2}$.

Commercial solutions that combine measurement irradiation with wireless data transfer technology are scarce and costly. The proposed architecture stands out from commercial solutions due to its low cost, flexibility, fast installation, modularity, automated data processing capacity and applicability in a wide range of research areas such as meteorological, environmental, and photovoltaic power generation, among others.

The proposed architecture also stands out from related studies for the model accuracy and the ability to connect to wireless networks, self-monitoring algorithms, and automated and cloud data processing capabilities.

\section{Patents}

This device is patent pending at the National Institute of Industrial Property under the number BR1020200199846.

Author Contributions: Á.B.d.R. conceived, designed and developed the prototypes' hardware and firmware, designed and accomplished the experiments and wrote the manuscript. E.d.M.F., C.A.C.d.S. provided ideas and improvements for the research, wrote and revised the manuscript. J.M.T.D. and W.F.A.J. conceived the project and promoted the guidelines. All authors have read and agreed to the published version of the manuscript.

Funding: The APC was funded by the Federal University of Campina Grande-UFCG.

Institutional Review Board Statement: Not applicable.

Informed Consent Statement: Not applicable.

Data Availability Statement: In our article, all the data are disclosed and explained in different parts of the article.

Acknowledgments: The authors would like to thank the Graduate Program in Mechanical Engineering (PPGEM) of the Federal University of Campina Grande (UFCG) for the contribution of its structure, the Coordination for the Improvement of Higher Education Personnel (CAPES) for the financing of the research through the granting of a research scholarship and M.Sc. researchers in Mechanical Engineering Emerson da Trindade Marcelino (UFPE), M.Sc. Computer Sciences Armando Barbosa Sobrinho (UFAL) and Mechanical Engineer Allan Marques for his assistance during the research development. The third author also acknowledges the National Council for Scientific and Technological Development (CNPq) for funding the Research Productivity Grant (Process $\mathrm{N}^{\circ}$. 304493/2019-8).

Conflicts of Interest: The authors declare no conflict of interest. 


\section{References}

1. Rus-Casas, C.; Hontoria, L.; Fernández-Carrasco, J.I.; Jiménez-Castillo, G.; Muñoz-Rodríguez, F. Development of a utility model for the measurement of global radiation in photovoltaic applications in the internet of things (IoT). Electronics 2019, 8, 304.

2. Slávik, Č.; Čekon, M. Correction factor estimating of silicon pin photodiode derived from outdoor longterm measurement. In Proceedings of the 4th International Conference on Applied Technology, Leuven, Belgium, 15-17 September 2016.

3. Shafa, M.; Luo, S.; Tong, X.; Farooq, M.U.; Gao, L.; Zhou, Z. Low cost pyranometer for broad range and its credibility check with standard pyranometer. J. Nanoelectron. Optoelectron. 2015, 10, 119-125. [CrossRef]

4. Hukseflux Thermal Sensors. PV Monitoring and Meteorological Industries Prepare for Revised Pyranometers Standard ISO 9060:2018. 2018. Available online: https:/ / www.hukseflux.com/applications/meteorology-surface-energy-flux-measurement/ new-iso-90602018-standard-do-your (accessed on 15 April 2019).

5. Martínez, M.A.A.; Andújar, J.M.; Enrique, J.M. A new and inexpensive pyranometer for the visible spectral range. Sensors 2009, 9, 4615-4634. [CrossRef]

6. Benghanem, M. Measurement of meteorological data based on wireless data acquisition system monitoring. Appl. Energy 2009, 86, 2651-2660. [CrossRef]

7. Müller, S.; Wiener, P.; Bürger, A.; Nimis, J. IoT for All: Architectural design of an extensible and lightweight IoT analytics platform. In Proceedings of the 2017 International Conference on Industrial Engineering and Systems Management (IESM), Saarbrücken, Germane, 11-13 October 2017.

8. Kim, J.; Rhee, J.; Yang, S.; Lee, C.; Cho, S.; Kim, Y. Multilayer Perceptron Model to Estimate Solar Radiation with a Solar Module. J. Biosyst. Eng. 2018, 43, 352-361.

9. Lima, J.F. Previsão de Irradiação solar no Nordeste do Brasil Empregando o Modelo WRF Ajustado por Redes Neurais Artificiais (RNAs). Ph.D. Thesis, Instituto Nacional de Pesquisas Espaciais (INPE), São José dos Campos, SP, Brazil, 2015.

10. Rocha, Á.B.D.; Fernandes, E.D.M.; Dos Santos, C.A.C.; Diniz, J.M.T.; Junior, W.F.A. Development and Validation of an Autonomous System for Measurement of Sunshine Duration. Sensors 2020, 20, 4606. [CrossRef] [PubMed]

11. Nwankwo, S.N.; Nnabuchi, M.N.; Ekpe, J.E. Construction and Characterization of a Pyranometer Using Locally Available Materials for Global Solar Radiation Measurement. Asian Transact. Basic Appl. Sci. 2012, 26, 4.

12. Balan, M.C.; Damian, M.; Jäntschi, L. Preliminary results on design and implementation of a solar radiation monitoring system. Sensors 2008, 8, 963-978. [CrossRef] [PubMed]

13. Garrity, S.R.; Vierling, L.A.; Bickford, K. A simple filtered photodiode instrument for continuous measurement of narrowband NDVI and PRI over vegetated canopies. Agric. For. Meteorol. 2010, 150, 489-496. [CrossRef]

14. e Silva, R.A.; da Silva, V.P.R.; Cavalcanti, E.; dos Santos, D.N. Study of the variability of solar radiation in northeast Brazil. Rev. Bras. Mr. Agric. Ambient. 2010, 14, 501-509.

15. Díaz, M.; Martín, C.; Rubio, B. State-of-the-art, challenges, and open issues in the integration of Internet of things and cloud computing. J. Netw. Comput. Appl. 2016, 67, 99-117. [CrossRef]

16. Da Xu, L.; He, W.; Li, S. Internet of things in industries: A survey. IEEE Trans. Ind. Inform. 2014, 10, 2233-2243. [CrossRef]

17. Asthon, K. That 'Internet of Things' Thing. RFID J. 2010, 22, 97-114.

18. Aazam, M.; Zeadally, S.; Harras, K.A. Offloading in fog computing for IoT: Review, enabling technologies, and research opportunities. Futur. Gener. Comput. Syst. 2018, 87, 278-289. [CrossRef]

19. Khan, M.A.; Salah, K. IoT security: Review, blockchain solutions, and open challenges. Futur. Gener. Comput. Syst. 2018, 82, 395-411. [CrossRef]

20. Shah, A.S.; Nasir, H.; Fayaz, M.; Lajis, A.; Shah, A. A review on energy consumption optimization techniques in IoT based smart building environments. Information 2019, 10, 108. [CrossRef]

21. Lowry, J.H.; Mendlowitz, J.S.; Subramanian, N.M. Optical characteristics of Teflon $\mathrm{AF}^{\circledR}$ fluoroplastic materials. Opt. Eng. 1992, 31, 1982-1985. [CrossRef]

22. Valík, A.; Brázdil, R.; Zahradníček, P.; Tolasz, R.; Možný, M.; Řezníčková, L. Measurements of sunshine duration by automatic sensors and their effects on the homogeneity of long-term series in the Czech Republic. Clim. Res. 2019, 78, 83-101. [CrossRef]

23. Medugu, D.W.; Burari, F.W.; Abdulazeez, A.A. Construction of a reliable model pyranometer for irradiance measurements. African J. Biotechnol. 2010, 9, 1719-1725. [CrossRef]

24. Semiconductors, V. Silicon PIN Photodiode. 2021, pp. 1-5. Available online: https://www.vishay.com/docs/81502/bpv10.pdf (accessed on 19 March 2021).

25. Sze, S.M.; NG, K.K. Physics of Semiconductor Devices Physics of Semiconductor Devices; Wiley: Hoboken, NJ, USA, 2007; Volume 3, p. 739.

26. Wong, J. A collection of amp applications. In Application Note AN-106; Analog Devices: Norwood, MA, USA, 1992.

27. Mesquita, J.; Guimaraes, D.; Pereira, C.; Santos, F.; Almeida, L. Assessing the ESP8266 WiFi module for the Internet of Things. In Proceedings of the 2018 IEEE 23rd International Conference on Emerging Technologies and Factory Automation (ETFA), Torino, Italy, 4-7 September 2018; pp. 784-791.

28. Thaker, T. ESP8266 based implementation of wireless sensor network with Linux based Web-Server. In Proceedings of the 2016 Symposium on Colossal Data Analysis and Networking (CDAN), Indore, India, 13-16 March 2016.

29. Nettikadan, D.; Raj, S. Smart Community Monitoring System using Thingspeak IoT Plaform. Artic. Int. J. Appl. Eng. Res. 2018, 13, 13402-13408. 
30. Apurva, L.M.N. IoT based Solar Monitoring System. Int. J. Sci. Technol. Eng. 2016, 3, 1-18.

31. Oliveira, G.M.; Costa, D.C.; Cavalcanti, R.J.; Oliveira, J.P.; Silva, D.R.; Nogueira, M.B.; Rodrigues, M.C. Comparison between MQTT and WebSocket Protocols for IoT Applications Using ESP8266. Work. Metrol. Ind. 4.0 IoT 2018, 3, $236-241$.

32. Yassein, M.B.; Shatnawi, M.Q.; Aljwarneh, S.; Al-Hatmi, R. Internet of Things: Survey and open issues of MQTT protocol. In Proceedings of the 2017 International Conference on Engineering \& MIS (ICEMIS), Monastir, Tunisia, 8-10 May 2017.

33. Singh, M.; Rajan, M.A.; Shivraj, V.L.; Balamuralidhar, P. Secure MQTT for Internet of Things (IoT). In Proceedings of the 2015 Fifth International Conference on Communication Systems and Network Technologies, Gwalior, India, 4-6 April 2015 ; pp. 746-751.

34. Rosli, R.S.; Habaebi, M.H.; Islam, M.R. Characteristic analysis of received signal strength indicator from esp8266 wifi transceiver module. In Proceedings of the 2018 7th International Conference on Computer and Communication Engineering (ICCCE), Kuala Lumpur, Malaysia, 19-20 September 2018; pp. 504-507.

35. Marcelino, E.D.T.; Diniz, J.M.T.; Rocha, A.; Fernandes, E.D.M.; Duarte, R.; Júnior, W.A. Experimentation of a low-cost electronic system for measurement of the ultraviolet radiation index to the city of Campina Grande, Brazil. In Proceedings of the 25th International Congress of Mechanical Engineering, Uberlândia, Brazil, 20-25 October 2019.

36. King, D.L.; Myers, D.R. Silicon-photodiode pyranometers: Operational characteristics, historical experiences, and new calibration procedures. In Proceedings of the Conference Record of the Twenty Sixth IEEE Photovoltaic Specialists Conference, Anaheim, CA, USA, 29 September-3 October 1997; pp. 1285-1288.

37. Kern, E.C., Jr. Calibration methods for silicon photodiode pyranometers used in rotating shadowband radiometers. In Proceedings of the Solar PACES Conference, Perpignan, France, 20 April 2010.

38. Myers, D.R. Quantitative analysis of spectral impacts on silicon photodiode radiometers. In Proceedings of the 40th ASES National Solar Conference, Raleigh, NC, USA, 17-20 May 2011; Volume 1, pp. 97-102.

39. Mcarthur, L.J.B.; Dahlgren, L.; Dehne, K.; Hamalainen, M.; Leidquist, L.; Maxwell, G.; Wells, C.V.; Wardle, D.I. Using Pyranometers in Tests of Solar Energy Converters: Step-by-Step Instructions; International Energy Agency Solar Heating and Cooling Program Task 9f: Downsview, ON, Canada, 1995; p. 50.

40. Fanney, A.H.; Davis, M.W.; Dougherty, B.P.; King, D.L.; Boyson, W.E.; Kratochvil, J.A. Comparison of photovoltaic module performance measurements. J. Sol. Energy Eng. 2006, 128, 152-159. [CrossRef]

41. Brooks, D.R. Monitoring Solar Radiation and Its Transmission through the Atmosphere. Available online: http://instesre.com/ papers/UsingTheSun/using.htm (accessed on 19 May 2019).

42. Becker, C.T.; Melo, M.M.M.S.; Costa, M.N.d.M.; Ribeiro, R.E.P. Caracterização Climática das Regiões Pluviometricamente Homogêneas do Estado da Paraíba. Rev. Bras. Geogr. Physics 2011, 4, 286-299. [CrossRef]

43. Menezes, H.E.A.; Brito, J.I.B.D.; Santos, C.A.C.D.; Silva, L.L.D. A relação entre a temperatura da superfície dos oceanos tropicais e a duração dos veranicos no estado da Paraíba. Rev. Bra. Meteorol. 2008, 23, 152-161. [CrossRef]

44. Correa, M.B.R.; Oliveira, A.C. Atlas Eólico do Estado da Paraíba. Available online: https://paraiba.pb.gov.br/diretas/secretariade-infraestrutura-dos-recursos-hidricos-e-do-meio-ambiente/arquivos/atlas-pb-2017.pdf/view (accessed on 10 July 2019).

45. Ghayekhloo, M.; Ghofrani, M.; Menhaj, M.B.; Azimi, R. A novel clustering approach for short-term solar radiation forecasting. Sol. Energy 2015, 122, 1371-1383. [CrossRef]

46. Reda, I. Method to Calculate Uncertainty Estimate of Measuring Shortwave Solar Irradiance Using Thermopile and Semiconductor Solar Radiometers; National Renewable Energy Lab. (NREL): Golden, CO, USA, 2011.

47. Miot, H.A. Análise de concordância em estudos clínicos e experimentais. J. Vasc. Bras. 2016, 15, 89-92. [CrossRef]

48. Diniz, J.M.T.; Dantas, R.T.; Fideles Filho, J. Variabilidade espaço-temporal da temperatura e difusividade térmica do solo de Lagoa Seca-PB. Rev. Ambient. Agua 2014, 9, 722-736.

49. Tiepolo, G.M.; Pereira, E.B.; Junior, J.U.; Pereira, S.V.; Gonçalves, A.R.; Lima, F.J.L.; Costa, R.S.; Alves, A.R. Atlas de energia solar do estado do Paraná. Rev. Brasileira de Energia Solar 2018, 9, 1-10.

50. Willmott, C.J.; Ackleson, S.G.; Davis, R.E.; Feddema, J.J.; Klink, K.M.; Legates, D.R.; Rowe, C.M. Statistics for the evaluation and comparison of models. J. Geoph. Res. 1985, 90, 8995-9005. [CrossRef]

51. Heinemann, A.B.; Van Oort, P.A.; Fernandes, D.S.; Maia, A.D.H.N. Sensitivity of APSIM/ORYZA model due to estimation errors in solar radiation. Bragantia 2012, 71, 572-582. [CrossRef]

52. Boyd, M. Methodology, and calculator for high precision regression fits of pyranometer angular responsivities and the associated uncertainties. Sol. Energy 2015, 119, 233-242. [CrossRef]

53. Lave, M.; Stein, J.; Smith, R. Solar Variability Datalogger. J. Sol. Energy Eng. Trans. 2016, 138, 138-143. [CrossRef]

54. Dunn, L.; Gostein, M.; Emery, K. Comparison of pyranometers vs. PV reference cells for evaluation of PV array performance. In Proceedings of the 2012 38th IEEE Photovoltaic Specialists Conference, Austin, TX, USA, 3-8 June 2012; pp. $2899-2904$.

55. Tohsing, K.; Phaisathit, D.; Pattarapanitchai, S.; Masiri, I.; Buntoung, S.; Aumporn, O.; Wattan, R. A development of a low-cost pyranometer for measuring broadband solar radiation. J. Phys. Conf. Ser. 2019, 1380, 012045. [CrossRef] 